\title{
High sensitivity of domestic pigs to intravenous infection with HEV
}

\author{
Lisa Dähnert ${ }^{1}$, Martin Eiden ${ }^{1}$, Josephine Schlosser ${ }^{2}$, Christine Fast $^{1}$, Charlotte Schröder $^{3}$, Elke Lange ${ }^{3}$, \\ Albrecht Gröner ${ }^{4}$, Wolfram Schäfer ${ }^{5}$ and Martin H. Groschup ${ }^{1 *}$ (D)
}

\begin{abstract}
Background: Hepatitis E virus (HEV) is one major cause of acute clinical hepatitis among humans throughout the world. In industrialized countries an increasing number of autochthonous HEV infections have been identified over the last years triggered by food borne as well as - to a much lower degree - by human to human transmission via blood transfusion. Pigs have been recognised as main reservoir for HEV genotype 3 (HEV-3), and zoonotic transmission to humans through undercooked/raw meat is reported repeatedly. The minimal infectious dose of HEV-3 for pigs is so far unknown.

Results: The minimum infectious dose of HEV-3 in a pig infection model was determined by intravenous inoculation of pigs with a dilution series of a liver homogenate of a HEV infected wild boar. Seroconversion, virus replication and shedding were determined by analysis of blood and faeces samples, collected over a maximum period of 91 days. A dose dependent incubation period was observed in faecal shedding of viruses employing a specific and sensitive PCR method. Faecal viral shedding and seroconversion was detected in animals inoculated with dilutions of up to $10^{-7}$. This correlates with an intravenously (i.v.) administered infectious dose of only 6.5 copies in $2 \mathrm{ml}$ (corresponding to 24 IU HEV RNA/ml). Furthermore the first detectable shedding of HEV RNA in faeces is clearly dose dependent. Unexpectedly one group infected with a $10^{-4}$ dilution exhibited prolonged virus shedding for more than 60 days suggesting a persistent infection.
\end{abstract}

Conclusion: The results indicate that pigs are highly susceptible to i.v. infection with HEV and that the swine model represents the most sensitive infectivity assay for HEV so far. Considering a minimum infectious dose of $24 \mathrm{IU} \mathrm{RNA} / \mathrm{ml}$ our findings highlights the potential risk of HEV transmission via blood and blood products.

Keywords: HEV, Minimal infectious dose, Swine, In vivo

\section{Background}

Hepatitis E is caused by Hepatitis E virus (HEV) which is a major cause of acute hepatitis throughout the world with a total number of 44,000 HEV-related deaths in 2015 [1]. Hepatitis E virus is a small, quasi-enveloped, single-stranded RNA virus and a member of the Hepeviridae family. Novel taxonomic classification consists of the two genera Piscihepevirus and Orthohepevirus encompassing species $A-D$. All mammalian HEV isolates have been attributed to species Orthohepevirus $A$ [2] and are further grouped into genotypes 1-8. Although

\footnotetext{
* Correspondence: martin.groschup@fli.de

${ }^{1}$ Institute of Novel and Emerging Infectious Diseases,

Friedrich-Loeffler-Institut, Südufer 10, 17493 Greifswald, Insel Riems, Germany

Full list of author information is available at the end of the article
}

displaying a highly diverse group on molecular level, all genotypes evidently belong to one serotype [3, 4].

Genotype 1 (HEV-1) and 2 (HEV-2) are restricted to humans and are the main cause of endemic outbreaks in developing countries in Asia, Africa and Central America $[5,6]$. The transmission of these isolates mainly occurs by the faecal-oral route due to poor sanitation and contaminated water [3].

HEV genotypes 3 (HEV-3) and 4 (HEV-4) dominate in developed countries and are the main source for autochthonous human cases [7]. In Europe, North America, Australia and New Zealand HEV-3 is reported as causative agent for these autochthone HEV infections $[8,9]$. In addition, infections with gt 4 have been observed in China and Japan [10-12]. Besides humans various wild and domesticated animal species such as wild boar and 
pigs [13] have been found to carry HEV-3 and HEV-4; HEV-3 has also been detected in deer [14, 15] and rabbits $[16,17]$. HEV-3/4 therefore is a zoonosis and pigs as well as wild boar represent the main reservoirs [7, 18]. Domestic pig populations worldwide frequently include viraemic animals and high HEV seroprevalences on herd level $[5,19,20]$. The exact pathogenesis of the HEV infection in pigs has still to be clarified. Naturally the infection occurs by faecal-oral transmission route which has been experimentally shown by a number of studies [21-24], albeit the intravenous infection is used most frequently in experimental challenge studies [22, 24-29]. Infected animals have high viral loads of HEV RNA mainly in the liver accompanied by faecal virus shedding in high concentrations [22, 23, 25, 26, 28]. Remarkably, no clinical symptoms were observed in general $[5,22$, $25,26]$. Domestic pigs are a suitable and sensitive model for HEV-3 infection studies since they are also susceptible to human HEV-3 isolates [27].

The HEV-3 transmission from animals to humans via the consumption of infected undercooked/raw meat has been documented in numerous cases [7, 9]. Furthermore, HEV has been detected in processed food products like sausages in Germany [30], Italy [31] and France [9]. Regional distinctions such as raw meat consumption, liver delicacies and close proximity to livestock can have an influence on the exposure towards HEV [8, 32]. Additionally, people with work-related exposure to reservoir animals such as veterinarians, slaughterhouse personal, hunters or stable hands show significantly higher seroprevalences compared to the general population [33, 34].

In general HEV causes a wide range of symptoms, from subclinical to acute hepatitis with icterus up to fulminant hepatic failure [13]: The strictly human pathogenic genotypes HEV-1/2 the main source of endemic outbreaks - cause frequently an acute self-limited hepatitis with icterus and affect in general younger patients [35]. HEV-1 infections in pregnant women are often associated with severe courses, especially in the third trimester $[3,13]$. HEV-3 and HEV-4 strains can additionally trigger extrahepatic manifestations but exhibit significantly lower mortality [36]. In contrast to HEV-1, HEV-3 infections can cause chronic and persistent infections mainly in immunocompromised patients [37, 38]. So far the infectivity of HEV is not clearly understood and difficult to determine and due to the lack of a sensitive cell culture system. Since domestic pig are highly susceptible to HEV the porcine model was selected to perform an endpoint titration study based on the application of serial dilutions of a HEV-3 positive liver homogenate. Since swine share many similarities with humans in physiology and immunology the determination of the minimal infectious dose provides important indications also for HEV infectivity in humans.

\section{Results}

\section{Inoculum}

The infection studies were carried out using tenfold dilutions of the inoculum from $10^{-2}$ up to $10^{-9}$. Corresponding ct-values, copy numbers and IU are summarized in Table 1. $3.7 \mathrm{IU}$ correspond to $1 \mathrm{copy} / \mu \mathrm{l}$ RNA which was calculated from standard curves of both PCR assays used in this study [39] (Additional files 1 and 2). According to this calculation, a $10^{-2}$ dilution of the experimentally infected liver contained $9.4 \times 10^{5}$ copies $\left(3.4 \times 10^{6} \mathrm{IU}\right)$ in $2 \mathrm{ml}$ respectively.

\section{Clinical parameters and pathology}

Through-out the whole observation period none of the animals showed a febrile response or any clinical signs consistent with hepatitis. Additionally, no signs typical for viral hepatitis were seen at gross examination after necropsy.

\section{Virus detection in faeces and serum intra-vitam}

Viral RNA was detected in the faeces of all groups up to a dilution of $10^{-7}$. In the first experimental set up covering homogenate dilutions from $10^{-2}$ to $10^{-4}$ over an observation period of 27 days (Fig. 1) viral shedding was observed in all three groups. First detection of viral RNA was in the group $10^{-2}$ at 9 dpi (pig T1-14) followed by groups $10^{-3}$ at $15 \mathrm{dpi}$ and $10^{-4}$ at $17 \mathrm{dpi}$. Due to this delayed onset it was decided to extend the observation period for the second experimental set up for up to 91 days. The second $10^{-4}$ group started with viral shedding also at $17 \mathrm{dpi}$, followed by the group $10^{-5}$ at $27 \mathrm{dpi}$. Viruses started to be shed within a time frame of six days for all animals within all groups of the first experiment and these two groups in the second experiment. In the remaining groups inoculated with higher HEV dilutions, a more variable time frame of viral

Table 1 RT-qPCR Values of the inocula after infection

\begin{tabular}{|c|c|c|c|c|c|c|}
\hline \multirow{2}{*}{$\begin{array}{l}\text { Exp. } \\
\text { No. }\end{array}$} & \multirow{2}{*}{$\begin{array}{l}\text { Dilution } \\
\text { Group }\end{array}$} & \multicolumn{5}{|c|}{ Inoculum } \\
\hline & & $\begin{array}{l}\mathrm{CT}- \\
\text { Value }\end{array}$ & $\begin{array}{l}\text { cop/ } / \mu l \\
\text { RNA }\end{array}$ & $\mathrm{cop} / \mathrm{ml}^{\mathrm{t}}$ & cop/dose $e^{t}$ & IU/dose ${ }^{t}$ \\
\hline \multirow[t]{3}{*}{1} & $10-2$ & 25,6 & 13,010 & $467.853,40$ & $935.706,80$ & $3.443 .401,02$ \\
\hline & $10-3$ & 28,7 & 139 & $49.642,46$ & $99.284,92$ & $365.368,51$ \\
\hline & $10-4$ & 33,0 & 5,61 & $2.003,56$ & $4.007,11$ & $14.746,17$ \\
\hline \multirow[t]{6}{*}{2} & $10-4$ & 32,2 & 10 & $3.607,11$ & $7.214,22$ & $26.548,33$ \\
\hline & $10-5$ & 35,5 & 0,91 & 325,71 & 651,42 & $2.397,23$ \\
\hline & $10-6$ & no ct & - & - & $65,1^{\mathrm{a}}$ & $239,70^{*}$ \\
\hline & $10-7$ & no ct & - & - & $6,5^{\mathrm{a}}$ & $24,00^{*}$ \\
\hline & $10-8$ & no ct & - & - & $0,65^{a}$ & $2,40^{*}$ \\
\hline & $10-9$ & no ct & - & - & $0,065^{a}$ & $0,24^{*}$ \\
\hline
\end{tabular}

Viral copy numbers were calculated from $\mathrm{CT}$ values determined by RT-qPCR (HEV copies/ $\mu \mathrm{l}$ RNA), volume of dose applied was $2 \mathrm{ml}$, ${ }^{t}$ calculated based on HEV copies/ $\mu$ I RNA (see Additional files 1 and 2$)^{a}$ extrapolated values 


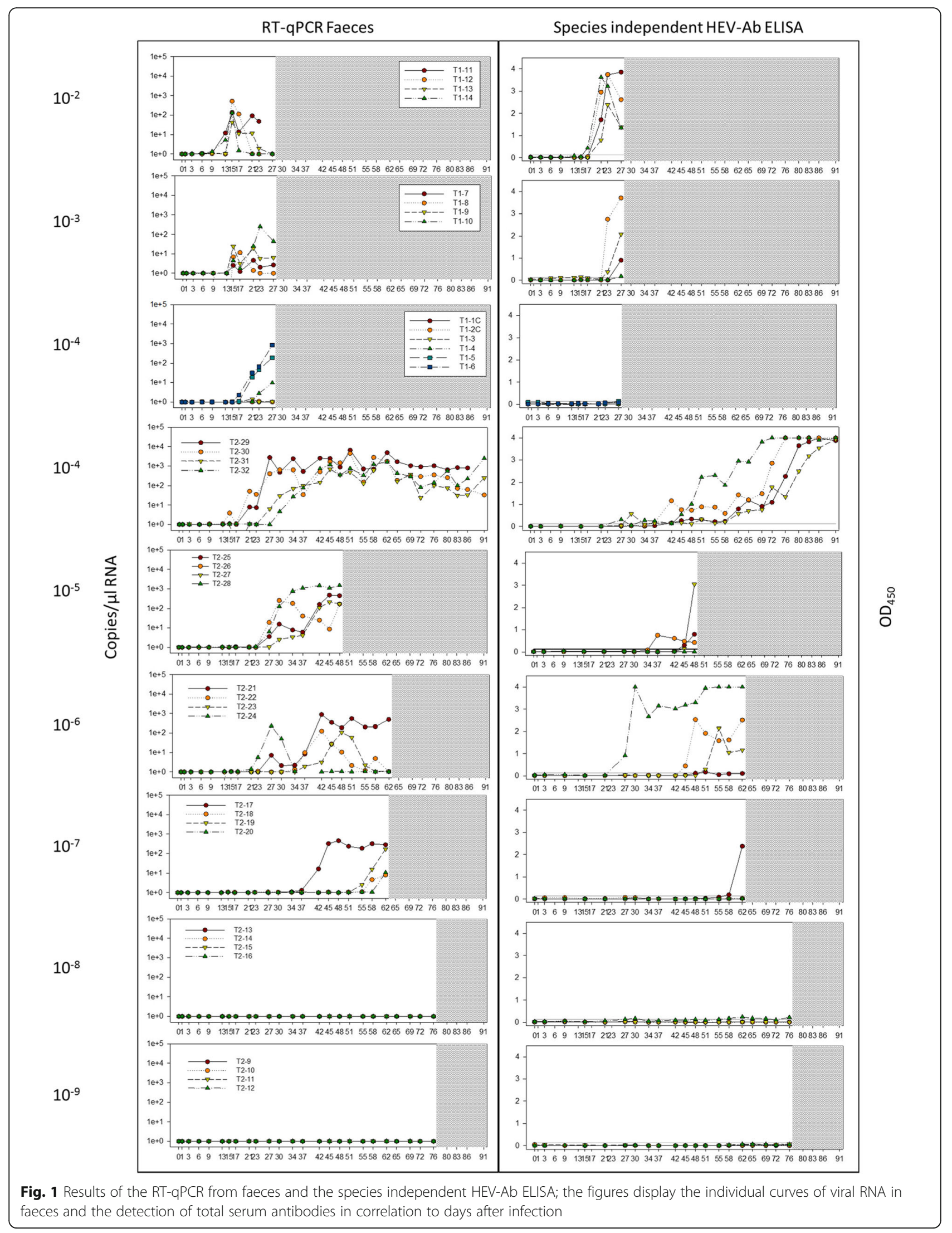


shedding was obvious. In group $10^{-6}$, pig T2-24 shed from $21 \mathrm{dpi}-30 \mathrm{dpi}$. The remaining animals of this group started one by one after $27 \mathrm{dpi}, 34 \mathrm{dpi}$, and 37 dpi. In group $10^{-7}$ pigs shed the virus until end of experiment; pig T2-17 started shedding virus at $37 \mathrm{dpi}$, while the other animals in this group started shedding at $55 \mathrm{dpi}, 58 \mathrm{dpi}$ and $62 \mathrm{dpi}$.

The majority of animals had between 1.3 and 51.7 HEV copies/ $\mu$ l RNA in the $10 \%$ faecal suspension initially and reached a plateau of about $10^{3} \mathrm{HEV}$ copies/ $\mu \mathrm{l}$ RNA eventually. Only individual animals of the $10^{-4}$ and the $10^{-5}$ group of the second experiment (Fig. 1) occasionally excreted six fold higher viral loads (up to $6.6 \times 10^{3}$ HEV copies/ $\mu$ l RNA) in their faeces.

Viral clearance was detected in group $10^{-2}$ in which shedding of HEV RNA in faeces ceased in three out of four pigs (pig T1-12, pig T1-13, T1-14) after a mean of $7 \mathrm{~d}( \pm 2.7)$. One individual (pig T1-11) remained positive till the end of the observation period on day 23. Unfortunately on day 27 (necropsy) no faeces was available from this animal for testing. In the $10^{-3}$ group only one animal (pig T1-08) cleared the virus before necropsy (27 dpi) 23 days dpi. No viral clearance was observed in the $10^{-4}$ group in both experiments even after $91 \mathrm{dpi}$. For group $10^{-5}$ an at least $18 \mathrm{~d}$ period of faecal shedding was seen with no clearance till the end of the observation period of $49 \mathrm{dpi}$. In group $10^{-6}$ virus clearance occurred at very diverse intervals including $11 \mathrm{~d}$ (pig T224), 21d (pig T2-23), 28d (pig T2-22) and more than $35 \mathrm{~d}$ (pig T2-21), and in group $10^{-7}$ the animals shed virus for at least $36 \mathrm{~d}$ (pig T2-17) or for 7, 4 or 1 days before being euthanized. Neither in the dilution $10^{-8}$ nor in the dilution $10^{-9}$ signs of virus replication or shedding were observed at all over a period of $76 \mathrm{dpi}$.

The detection of HEV RNA in serum was only sporadic and with low viral amounts (Additional files 2). Detection of viral RNA in serum samples at more than two consecutive sampling time points was only observed for groups $10^{-4} / 2$ (pig T2-29, pig T2-30, pig T2-31, pig T2-32), $10^{-5}$ (pig T2-25, pig T2-27, pig $\mathrm{T} 2-28$ ) and $10^{-7}$ (pig T2-17) after $24 \mathrm{dpi}, 34 \mathrm{dpi}$ and 58 dpi respectively.

\section{Infectivity titre of liver}

The infectivity in the liver tissue used for the inoculation can be quantified by the calculation of an $\mathrm{ID}_{50}$ according to Spearman and Kärber $[40,41]$ under particular assumptions: Restriction to an observation period of 27 days and in the case of longer incubation times the first positive animal within the group. The calculated titre was $6.3 \times 10^{5} \mathrm{ID}_{50}$ per $1 \mathrm{ml}$ liver tissue which represents $4.4 \times 10^{5}$ infectious units $/ \mathrm{ml}$. Setting this result in relation to the quantitation of HEV RNA in the liver inoculum 773 IU HEV RNA correspond to one infectious unit (for calculations see Additional file 3).

\section{Antibody detection}

Seroconversion started in all animals after the excretion of viral RNA in faeces. Pigs seroconverted in group $10^{-2}$ at $17 \mathrm{dpi}$, group $10^{-3}$ at $23 \mathrm{dpi}$, group $10^{-4}$ at $27 \mathrm{dpi}$, $10^{-5}$ at $37 \mathrm{dpi}, 10^{-6}$ at $27 \mathrm{dpi}$ and $10^{-7}$ at $58 \mathrm{dpi}$. The interval between detection of $\mathrm{HEV}$ in faeces and seroconversion was $7.0 \pm 1.0$ days for group $10^{-2}, 11 \pm 1.7$ days for group $10^{-3}, 12.8 \pm 12.8$ days for group $10^{-4}$, $16.0 \pm 3.5$ days for group $10^{-5}, 13.3 \pm 7.2$ days for group $10^{-6}, 31.0 \pm 0.0$ days for group $10^{-7}$. In one case (pig $\mathrm{T} 2-32)$ seroconversion was determined prior to virus detection which can be explained by the oscillation of corresponding OD values around the cut-off at sampling days 27 and 30 followed by a strong increase from day $34 \mathrm{on}$. HEV antibodies were assessed by the species independent HEV-Ab ELISA detecting total serum antibodies (e.g. IgG, IgM, IgA) in blood (Fig. 1). In the Priocheck HEV Ab porcine ELISA which only detects IgG, seroconversion was generally observed three to ten days later (Additional file 4). An exception was found for animals in the $10^{-7}$ group, where seroconversion was detected by both ELISA's at the same day. No seroconversion was observed in the $10^{-8}$ and $10^{-9}$ groups.

\section{Virus detection in organs}

All animals of the study were subjected to necropsy and blood, faeces, bile and tissue samples were taken and analysed by RT-qPCR for viral RNA (Tables 2 and 3). This included four different liver loci, the gallbladder, the hepatic lymph nodes, the spleen, the mesenteric lymph nodes and the mandibular lymph nodes. All animals which showed faecal shedding at necropsy were found HEV RNA positive in the bile and at least in two loci of the liver. The viral load of the gallbladder was considerably lower compared to bile itself. In pancreas no viral RNA was detected. In all other organs tested, individuals sporadically showed positive results. Corresponding data are shown in Tables 2 and 3.

\section{Sequencing}

The sequence of the hypervariable region of the inoculum (sequence and reference sequence KP294371 are shown in Additional file 5) was analysed by nested RT-PCR to monitor possible nucleotide exchanges after replication and passage through infected pigs. The original sequence displays a characteristic $\mathrm{C} / \mathrm{T}$ wobble sequence at position 2200. Likewise virus sequences from isolates from pigs of dilution groups $10^{-2}, 10^{-3}$, $10^{-4}, 10^{-5}, 10^{-6}$ and $10^{-7}$ displayed $\mathrm{C} / \mathrm{T}$ polymorphisms at this site. In addition to the nucleotide 2200 polymorphism one isolate (derived from animal (T2-28)) 


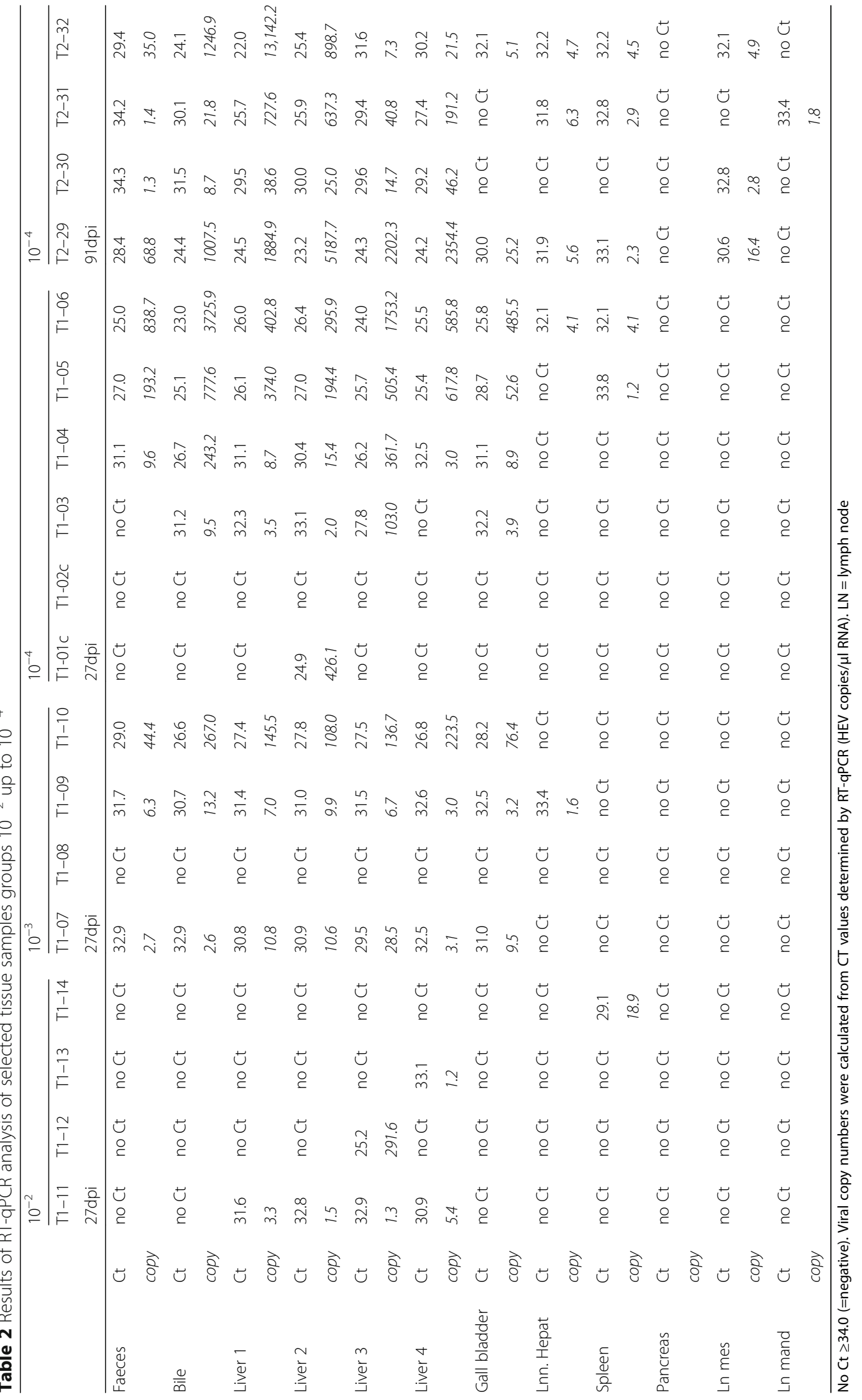




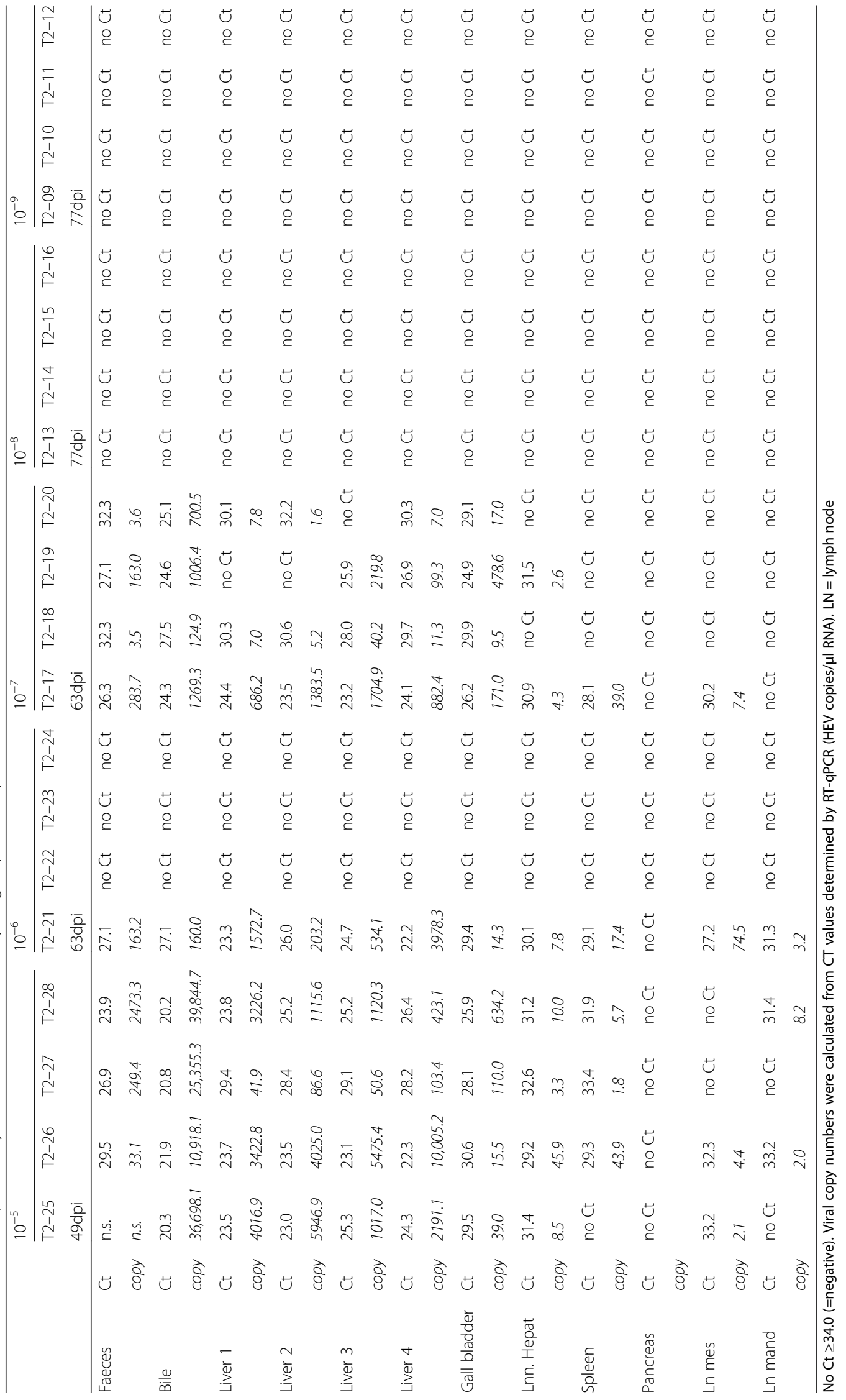


had a $\mathrm{C}$ to $\mathrm{T}$ exchange at position 2322. The alignment was done with a previously published full genome (KP294371). The wobble sequence translates into a proline/serine exchange. The point mutation in animal T2-28 was silent.

\section{Horizontal controls}

The two horizontal controls (T1-01c, T1-02c) showed no clinical or molecular evidence for a HEV infection and faecal samples were always negative for HEV RNA. However, one liver lobe of pig T1-01c gave a positive RT-qPCR result (shown in Table 2).

\section{Discussion}

An increasing number of human hepatitis E genotype 3 (HEV-3) infections has been observed in developed countries in the last decade. This is accompanied by a substantial proportion of HEV RNA positive blood products and a growing number of transfusion transmitted HEV infections [8]. The high incidence represents a major health concern especially for immunosuppressed patients or people with pre-existing liver diseases. This raises the question of the minimal infectious dose for intravenously applied HEV-3. For this purpose - based on the similarities of pig and human physiology and the assumption of pigs as reliable animal models for human HEV infection, a comprehensive dose-titration study was carried out in domestic pigs to determine the minimum infectious dose. The titration was based on serial dilutions of a HEV RNA positive liver homogenate of an experimentally infected wild boar [23]. It ranged from a $10^{-2}$ dilution up to a $10^{-9}$ dilution and was applied into groups of 4 pigs each. Seroconversion and viral shedding was observed up to a $10^{-7}$ dilution which corresponds to a minimal infection dose of 6.5 copies in $2 \mathrm{ml}$ total volume (according to 24 IU HEV RNA) for swine. In contrast to pigs, the infectious dose for humans is reportedly significantly higher: the transfusion of a platelet concentrate with residual plasma containing 70568892 IU HEV RNA was infectious [59]. In another study, the minimal infectious dose of HEV through transfusion was $3.6 \times 10^{4} \mathrm{IU}$ [42]. A minimal infectious dose for humans in the order of 10,000 IU HEV RNA was also reported by F. Rossi, IPFA [43]. However, a direct correlation is not possible, since our pig study evaluated liver derived HEV in contrast to human blood (plasma) products. The reduced infectivity of HEV positive plasma samples has been recently demonstrated in human liver chimeric mice [44]. In monkeys, intravenous HEV infection studies were performed as well, however generally using inocula from faecal samples. The used dosages encompassed titers of $6.4 \log _{10}$ copies/ml of a HEV-3 isolate [45] as well as $2.45 \times 10^{5} \mathrm{IU} / \mathrm{ml}$ for a HEV-4 and $7.51 \times 10^{5} \mathrm{IU} / \mathrm{ml}$ for a HEV-1 isolate [46]. Similar dosages were used in a recent study [47] using different HEV-1 isolates $\left(3.5-6.4 \log _{10} \mathrm{IU} / \mathrm{ml}\right)$ and HEV-3 isolates (2.5-9.5 $\log 10 \mathrm{IU} / \mathrm{ml})$. In each case cynomolgus monkeys could be productively infected.

All infected animals remained asymptomatic and showed no signs of illness such as fever, reduced alertness nor weight loss throughout the experiment which is in line with previous studies in domestic pigs [24, 25, 28]. So far, only singular cases of icterus in HEV infected pigs [27] as well as the elevation of liver specific enzymes in infected wild boar [23] have been reported. This study established faeces as appropriate source to determine the course of virus replication in pigs via RT-qPCR due to weak and sporadic detection of viral RNA in serum with a general lower viral load. This is in accordance with previous reports [22, 48]. It is of special significance that the calculated copy number of 5 copies $/ \mathrm{ml}$ in the $10^{-7}$ dilution lies below the limit of detection of both PCR assays but is sufficient to infect pigs by the intravenous route. This is in accordance with a previous pig titration study where infectivity was observed below the RT-PCR detection limit [28]. In addition a clear correlation between applied dosage and incubation period was determined: A $10^{-2}$ dilution of the inoculum induced viral shedding at $9 \mathrm{dpi}$, followed by virus shedding at $15 \mathrm{dpi}\left(10^{-3}\right.$ dilution), $17 \mathrm{dpi}\left(10^{-4}\right.$ dilution) and 27 dpi (the $10^{-5}$ dilution) in at least one pig per group, on average $30 \mathrm{dpi}\left(10^{-6}\right.$ dilution) and on average 51 days $\left(10^{-7}\right.$ dilution). The subsequent dilutions also induce growing individual differences in onset of virus shedding varying from 6 to 9 days $\left(10^{-4}\right.$ group), $10-18$ days $\left(10^{-6}\right.$ group) up to 16 days $\left(10^{-7}\right.$ group). The increasing extension of incubation period raises the question regarding replication site and persistence of the virus. Further dilutions $\left(10^{-8}, 10^{-9}\right)$ of the inoculum induced no HEV infection. In contrast, in the aforementioned study none of the animals inoculated with dilutions below $10^{-4}$ were infected [28]. However a direct comparison of both studies was not possible, since the viral load was determined by Genomic Equivalents $(\mathrm{GE} / \mathrm{ml})$ and due to the use of faecal material for intravenous inoculation. Both sources are able to induce virus replication as reported in multiple studies. A comparison of these studies regarding onset and duration of virus shedding and seroconversion is difficult because applied doses are incomparable and inoculum sources were different: After i.v. application of HEV positive faeces ( $10 \%$ suspension) virus detection in faeces started $3 \mathrm{dpi}[25,26]$ or $7-14$ dpi [28] and took 1-3 weeks. Using inoculum from a HEV positive pig derived bile led to virus shedding from 3 dpi on [22]. Using high titre liver homogenates i.v. infected pigs started to excrete virus between 2 and 7 days and continued 12-52 days [24, 29]. In another study faecal RNA samples of infected pigs were detected 
at day 9 to 19 and faecal HEV excretion lasted 21-30 days [21]. Interestingly both sources harbour significant differences because blood as well as hepatocyte/liver derived HEV particles are enveloped and covered with cellular membranes in contrast to non-enveloped HEV from bile or faeces [49-51]. This envelope has been also detected in cell-culture produced HEV particles [50, 52] and appears to modulate infectivity in vitro as well as in vivo. The generation of quasi-enveloped HEV particles by hepatocytes and hepatoma cell lines [51] strongly indicates that HEV from liver homogenate harbors an envelope as well, but experimental data are still lacking. Cell culture derived enveloped HEV revealed an almost tenfold lower infectivity compared to non-enveloped faeces derived HEV in cell culture [53], which may be a consequence of inefficient cell attachment [54]. However, the findings are complicated by the fact, that human liver homogenate as well as faeces from HEV positive patients is capable to infect humanized chimeric mice in contrast to human plasma or cell-culture derived HEV [55]. Therefore the question how biochemical properties of HEV particles modulate infectivity needs further investigation.

A presumably faecal-oral transmission of HEV was observed by one of the horizontal controls (pig T1-01c) within the $10^{-4}$ group. The animal exhibited a HEV positive liver as determined by necropsy at $27 \mathrm{dpi}$. The first onset of viral shedding in this group was on $17 \mathrm{dpi}$ from pig T1-06 which leads to a maximum incubation period of 10 days. The reported periods between oral intake and HEV particles shed in faeces can range from $7.2 \mathrm{~d}$ [24] up to $22 \mathrm{~d}$ [22] and possibly even longer.

Antibody response and seroconversion were assessed by two ELISAs with different specifications: The AXIOM ELISA was a multispecies test for detecting total serum antibodies against HEV (including IgM, IgA and IgG) whereas the PrioCheck ELISA only detected porcine HEV specific IgG antibodies. Specific porcine IgM ELISAs were not available. In general the serum samples were confirmed positive in the AXIOM ELISA three to ten days before the porcine specific IgG ELISA which is consistent with a primary IgM related immune response followed by IgG response. However, no reliable conclusions can be drawn about the specific occurrence of IgM or IgA or of a mixture of both during the primary immune response. In any case IgA antibodies play an important role in the human immune response against HEV $[55,56]$.

Virus clearance could be observed in different groups examined: Three animals in group $10^{-2}$, one individual from $10^{-3}$ and three from the $10^{-6}$ dilution group cleared the infection within $7 d( \pm 2,7 d), 8 d$ and $9 \mathrm{~d}$ up to $27 \mathrm{~d}$ respectively. All remaining animals were subjected to necropsy prior to a possible virus clearance. All animals of the second $10^{-4}$ group displayed a prolonged infection where HEV RNA was detectable in faeces for more than 62 days. Necropsy samples of this group harboured high viral load in bile and liver samples. The $10^{-5}$ group exhibited faecal viral shedding for $22 \mathrm{~d}$ and individual animals from group $10^{-6}$ and $10^{-7}$ group for $35 \mathrm{~d}$ and $36 \mathrm{~d}$, respectively. Again, all animals showed high viral loads in bile and liver at necropsy. In general, HEV is considered to be a transient infection and viral clearance usually occurs within three weeks after first occurrence in faeces [22, 24]. The long-term viral shedding for more than 32 up to 62 days is therefore uncommon and possibly indicates a chronic or persistent infection. Only rare data from similar studies are available: HEV shedding was significantly increased by co-infection with Porcine Reproductive and Respiratory Syndrome Virus (PRRSV) and extended from 9.7 to 48.6 days [57]. However, all animals in this study had been pre-tested to be negative for PRRSV as well as Porcine circovirus 2 (PCV2). This analysis was continued with faeces samples from the second $10^{-4}$ group encompassing the whole observation period, to exclude a newly or internal acquired PRRSV and PCV2 infection. Again all samples were negative for both viruses. All animals showing prolonged viral shedding belonged to the dilutions $10^{-4}$ or higher, indicating a correlation between inoculated virus load and prolonged viral shedding. The $10-4 \mathrm{~g}$.

Another research study showed extended virus shedding in wild boars for more than 16 weeks [48]. Interestingly the animals showed high antibody titers as well, with apparently no influence on virus shedding and replication. The presence of neutralising antibodies within the context of a HEV infection has been shown in vivo $[58,59]$ and in vitro [58-60]. Other factors such as age and individual immune status should be taken into account as well.

It may be of interest that in humans various cases of chronic HEV-3 infections were reported in immunosuppressed patients [61]. For all other genotypes such a correlation has not been made so far.

\section{Conclusion}

In conclusion, this study determined an extremely low minimum infectious dose of HEV to elicit a productive infection in pigs. Additionally our work demonstrated a dose dependent incubation time in pig resulting in a delayed onset of virus replication and shedding. Moreover the study emphasises the potential risk of HEV transmission in humans via blood and blood products. Finally further investigations should be undertaken to determine and compare the infectivity through oral transmission. 


\section{Methods}

\section{Inoculum}

The inoculum used in this study was prepared from a highly HEV RNA positive liver of an experimentally infected wild boar from a previous HEV-3 infection study [23].

$20 \mathrm{~g}$ of liver tissue was grounded with mortar, pestle and sterile sea sand. The homogenate was then diluted 1:5 with sterile $1 \mathrm{x}$ phosphate buffered saline $(1 \mathrm{xPBS})$ to obtain a $20 \%$ dilution and centrifuged at $4400 \mathrm{~g}$ for 15 $\min$ at $4{ }^{\circ} \mathrm{C}$. The supernatant was eventually sterile-filtered through $0.22 \mu \mathrm{m}$ MILLEX-GP Syringe Filter Unit (Millipore, Ireland), aliquoted and stored at $-80^{\circ} \mathrm{C}$. The inoculum was titrated with the Logarithmic dilutions in sterile $1 \times$ PBS starting from a $10^{-2}$ dilution (referring to the original liver tissue) to $10^{-9}$. The $10^{-2}$ dilution was sterile filtered prior to inoculation and further dilutions. The corresponding inocula were prepared shortly before inoculation and kept on ice until use and administered intravenously (i.v.) to 4 animals/group.

\section{Experimental design}

The competent authority of the Federal State of Mecklenburg Western-Pomerania approved all described animal experiments based on European Directive 2010/ $63 / \mathrm{EU}$ and associated national regulation (reference number in Germany LALLF M-V/TSD/7221.3-2.1.014/ 10, LALLF M-V/TSD/7221.3-2.1-017/13).

For this study 38 domestic pigs (Large White breed) from a commercial breeder (animal husbandry, 18,196 Dummerstorf, Germany) were acquired and housed under containment level $3 *$ conditions. Healthy animals of compatible sizes and ages were allocated randomly to groups by animal technicians. Social incompatibilities were taken into account in few instances for animal welfare reasons. As the study was a titration experiment with a clear cut yes/no readout, the number of animals per group was set as described together with a biostatistician. The experimental design was part of the individualized animal experimental license (reference number in Germany LALLF M-V/TSD/7221.3-2.1.014/ 10, LALLF M-V/TSD/7221.3-2.1-017/13 according to the Germany animal welfare law ( $\$ 7$ paragraph 1 phrase 2 TierSchG) which was applied for and given after scientific and ethical assessment by an independent advisory board. After entry, the animals were divided into the experimental groups and held in quarantine for 2 weeks. Individuals of each group were housed together whereas each group was held in a separate stable unit. Complete change of clothes was mandatory before entry of each of the rooms. All animals were pretested for $\mathrm{HEV}$ and yielded negative PCR findings in faeces and serum as well negative HEV ELISA results. Due to facility limitations the study was divided in two experiments. The groups were randomly formed consisting of 4 animals each as described in Table 4. Two horizontal transmission control animals were included and kept with the $10^{-4}$ group. A blinded experimental and analysis design was not possible as researchers and animal technicians were supposed to carry out husbandry and experimental work in a defined way in order to mitigate (cross-) contamination risks: every day animal manipulations started in the low dose challenged animals, followed by intermediate dose challenged pigs and in high-dose animals eventually. Moreover, as only standardized quantitative data were obtained (e.g. body temperatures, qPCR (Ct-values and copy numbers) and ELISA derived data), blinding was not considered necessary.

After at least two weeks of acclimatisation negative HEV RNA and Anti-HEV-antibody results were reconfirmed by Rt-qPCR and ELISA. Additionally samples were examined by a novel multiplex PCR [62] (Results not shown) to exclude an influence of co-infection with other viral diseases (PRRSV, PCV2). The inoculation was done with $2.0 \mathrm{ml}$ inoculum intravenously given into the Vena cava cranialis.

Table 4 Experimental set up for the titration of highly HEV positive liver tissue in log steps in the porcine model

\begin{tabular}{|c|c|c|c|c|c|c|c|}
\hline \multirow[t]{2}{*}{ Exp. No. } & \multirow[t]{2}{*}{ Dilution = Group } & \multirow[t]{2}{*}{ Animal identity } & \multicolumn{2}{|l|}{ Animals } & \multirow[t]{2}{*}{ Sex } & \multirow{2}{*}{$\begin{array}{l}\text { Age at inoculation } \\
\text { in weeks }\end{array}$} & \multirow[t]{2}{*}{ Observation period } \\
\hline & & & infected & horizontal control & & & \\
\hline \multirow[t]{3}{*}{1} & $10^{-2}$ & Pig T1-11, $-12,-13,-14$ & 4 & - & $f / m$ & 10 & 27dpi \\
\hline & $10^{-3}$ & Pig T1-07, $-08,-09,-10$, & 4 & - & $f / m$ & 10 & 27dpi \\
\hline & $10^{-4}$ & Pig T1-01c -02c,-03, $-04,-05,-06$ & 4 & 2 & $f / m$ & 10 & $27 \mathrm{dpi}$ \\
\hline \multirow[t]{6}{*}{2} & $10^{-4}$ & Pig T2-29, $-30,-31,-32$ & 4 & - & $\mathrm{m}$ & 11 & 91dpi \\
\hline & $10^{-5}$ & Pig T2-25, $-26,-27,-28$ & 4 & - & $f / m$ & 11 & 49dpi \\
\hline & $10^{-6}$ & Pig T2-21, $-22,-23,-24$ & 4 & - & f & 11 & 63dpi \\
\hline & $10^{-7}$ & Pig T2-17, $-18,-19,-20$ & 4 & - & $f / m$ & 11 & 63dpi \\
\hline & $10^{-8}$ & Pig T2-13, $-14,-15,-16$ & 4 & - & $\mathrm{m}$ & 11 & 77dpi \\
\hline & $10^{-9}$ & Pig T2-09, $-10,-11,-12$ & 4 & - & $f$ & 11 & 77dpi \\
\hline
\end{tabular}

The dilution step of the homogenate as assigned the group designation, f-female, m-male, dpi-days post infection, -- none 
Animal behaviour and rectal body temperatures were checked daily. As described in previous studies body temperatures over $40{ }^{\circ} \mathrm{C}$ for at least two consecutive days were considered a febrile response [23, 48]. Depression, diarrhoea, vomitus, icterus, ascites and neurological symptoms were considered signs of acute hepatitis and would have led to an immediate removal and euthanasia of the animal.

During the experiments blood and faecal samples were taken regularly every two to three days. Blood was allowed to clot for $30 \mathrm{~min}$ at room temperature and then centrifuged at $2300 \mathrm{~g}$ for $12 \mathrm{~min}$. Serum was then collected, aliquoted and stored at $-20{ }^{\circ} \mathrm{C}$. From the faecal samples a $10 \%$ faecal suspension was made using $0.89 \%$ $\mathrm{NaCl}$-solution. After vortexing and centrifugation (4400 g, $4{ }^{\circ} \mathrm{C}, 20 \mathrm{~min}$ ) the supernatant was sterile filtrated using a sterile $0.22 \mu \mathrm{m}$ MILLEX-GP Syringe Filter Unit (Millipore, Ireland) and stored at $-20^{\circ} \mathrm{C}$. This solution was the starting point for RNA extraction.

At the end of the observation period all animals were slaughtered (electro stunning followed by exsanguination). Animals were euthanized by a veterinarian following EU and German animal welfare regulations and carcasses necropsied by a trained veterinary pathologist assisted by a necropsy technician. Necropsies were performed and samples from blood, faeces and bile as well as different tissue samples were taken for RNA extraction and stored at $-20^{\circ} \mathrm{C}$. Retrieved tissue samples were immediately immersed in $4 \%$ neutral buffered formalin.

\section{RNA and antibody detection}

A sample volume of $140 \mu \mathrm{l}$ of serum, bile and faecal filtrates were extracted manually with the QIAmp ${ }^{\circ}$ Viral RNA Mini Kit (QIAGEN GmbH, Hilden Germany) following the manufactures instructions and eluated in $50 \mu \mathrm{l}$ buffer. Manual RNA extraction from tissue samples was performed with the RNEasy ${ }^{\circ}$ Mini Kits (QIAGEN $\mathrm{GmbH}$, Hilden Germany). For this purpose $10 \mathrm{mg}$ of a tissue sample was homogenized in $600 \mu \mathrm{l}$ RLT buffer using TissueLyser II ${ }^{\bullet}$ (Qiagen). After centrifugation the supernatant was used for RNA extraction according to manufacturer's instructions. A heterologous internal control [63] was added to each extraction sample. Obtained RNA was stored at $-80{ }^{\circ} \mathrm{C}$ until further use.

To monitor the course of the infection a diagnostic quantitative real-time RT-PCR (RT-qPCR) targeting a fragment of ORF3 was performed. Primer, probes and protocol were used as previously reported [23, 39]. Each reaction containing $25 \mu \mathrm{L}$ had a final primer concentration of $0.8 \mu \mathrm{M}$ and of $0.1 \mu \mathrm{M}$ probe and $5 \mu \mathrm{l}$ RNA. RT-qPCR was carried out using the Quanti Tect Probe RT-PCR Kit (QIAGEN GmbH). The CFX96 ${ }^{\text {TM }}$ Real-Time System (BioRad Laboratories $\mathrm{GmbH}$, Munich, Germany) was set to $50{ }^{\circ} \mathrm{C}$ for $30 \mathrm{~min}$ for reverse transcription followed by denaturation/activation $95^{\circ} \mathrm{C}$ for $15 \mathrm{~min}$. DNA amplification was performed in 45 cycles consisting each of $95^{\circ} \mathrm{C}$ for $10 \mathrm{~s}, 55^{\circ} \mathrm{C}$ for $25 \mathrm{~s}$ and $72{ }^{\circ} \mathrm{C}$ for $25 \mathrm{~s}$ in immediate succession. The quantification of RNA (HEV copies/ $\mu$ l RNA) was performed by a standard curve based on serial dilutions of a HEV standard, which was included in each qRT-PCR run (Additional file 1). The copy number of HEV standards was calculated by a synthetic calibrator which consists of the qRT-PCR amplicon (81 nucleotides) and a T7-Promotor sequence at the $5^{\prime}$-end to allow in vitro transcription [39]. International Units/ml (IU) were calculated from the WHO International standard for HEV. This standard was provided by the Paul-EhrlichInstitut (PEI), Langen, Germany (PEI code 6329/10). All RT-qPCR results are given in HEV copies/ $\mu$ RNA (originating from $50 \mu \mathrm{l}$ elution volume). The corresponding cop/ $\mathrm{ml}$ (originating from $140 \mu \mathrm{l}$ fluid sample) were calculated by conversion factor of 357, 14 (elution volume divided by fluid sample volume) and is depicted in Additional file 2. The limit of detection of about $1 \mathrm{cop} / \mu \mathrm{l}$ is reached at ct-values of $\sim 35$. The limit of quantification corresponds to the $10^{-4} \mathrm{HEV}$ standard at 7 copies/ $\mu \mathrm{l}$. Viral loads below the lowest HEV standard were retested by an alternative HEV specific qRT-PCR [64].

To monitor the immunological responses, the serum samples were tested with two commercially available HEV ELISA kits. One was the species independent HEV-Ab ELISA (AXIOM, Bürstadt, Germany) [23] detecting total serum anti-HEV-antibodies. The other was the porcine specific Priocheck HEV Ab porcine ELISA (Mikrogen GmbH, Neuried, Germany), which is specific for serum Anti-HEV-IgG. Both were carried out and interpreted as described by the manufacturer.

\section{Sequencing}

To monitor and verify the identity of the inoculated compared to the replicated/excreted virus genome a 348 nucleotide long partial sequence of the hypervariable region (HVR) was recovered from corresponding faecal samples. SYBR Green-RT-qPCR followed by a SYBR Green nested PCR both with melting curve analysis was performed as described [39]. The resulting cDNA was sequenced by a commercial provider (Eurofins Genomics $\mathrm{GmbH}$, Ebersberg, Germany).

\section{Additional files}

Additional file 1: Amplification curve of HEV specific qRT-PCR. A) Amplification curve of HEV specific QRT-PCR targeting the HEV standard (red line) and the RNA extracts from the inocula (blue line). B) Standard curves were obtained by $\mathrm{Ct}$ values plotted against the log of starting quantity. C) Obtained Ct values and determined copy numbers (DOCX 219 kb)

Additional file 2: Determination of the conversion factor from copies per $\mu$ RNA to IU of the WHO standard (DOCX $16 \mathrm{~kb}$ ) 
Additional file 3: Calculation of the Infectivity titer of the Liver Used for Inoculation (DOCX $16 \mathrm{~kb}$ )

Additional file 4: Results of the RT-qPCR from serum and the porcine IgG HEV-Ab ELISA; The graphs display the individual curves of viral RNA in serum and the detection of Anti-HEV-lgG antibodies in correlation to days after infection (DOCX $462 \mathrm{~kb}$ )

Additional file 5: Alignment of the hypervariable region. Alignment done with Geneious version 10.2 created by Biomatters. Available from https://www.geneious.com (DOCX 244 kb)

\section{Abbreviations}

Ab: Antibody; dpi: Days post inoculation; ELISA: Enzyme-linked immunosorbent assay; f: Female; gt: Genotype; HEV: Hepatitis E Virus; HVR: Hypervariable region; i.v.: Intravenous; Ig: Immunglobulin; IU: International Unit: m: Male; PBS: Phosphate buffered saline; PCR: Polymerace chain reaction; PCV2: Porcine circovirus 2; PRRSV: Porcine reproductive and respiratory syndrome virus; RNA: Ribonucleic acid

\section{Acknowledgments}

We thank Hanan Sheik Ali for their profound help. In addition, we thank Birke Boettcher and Tobias Winterfeld, for their excellent technical support, Svenja Wiechert and Erika Hilbold for their excellent help during their internship and all animal caretakers for the excellent animal husbandry. This study was partially funded by a research grant from CSL Behring Marburg.

\section{Funding}

This project has received funding from the European Union's Horizon 2020 research and innovation program VetBioNet under grant agreement No 731014.

\section{Availability of data and materials}

All data generated or analysed during this study are included in this published article [and its supplementary information files].

\section{Authors' contributions}

Conceived and designed the experiments: JS, LD, ME, MHG. Performed the experiments and necropsy: LD, JS, CF, EL, CS, ME, AG. Analysed the Data: LD, JS, ME, CF, MHG. Wrote the paper: LD, JS, ME, MHG, WS. All authors have read and approved the manuscript.

\section{Ethics approval and consent to participate}

The competent authority of the Federal State of Mecklenburg Western-Pomerania approved all described animal experiments based on European Directive 2010/ 63/EU and associated national regulation (reference number in Germany LALLF M-V/TSD/7221.3-21.014/10, LALLF M-V/TSD/7221.3-2.1-017/13).

\section{Consent for publication}

Not applicable.

\section{Competing interests}

W. Schäfer is an employee and A. Gröner is a former employee of CSL Behring. The authors declare that they have no competing interests

\section{Publisher's Note}

Springer Nature remains neutral with regard to jurisdictional claims in published maps and institutional affiliations.

\section{Author details}

${ }^{1}$ Institute of Novel and Emerging Infectious Diseases,

Friedrich-Loeffler-Institut, Südufer 10, 17493 Greifswald, Insel Riems, Germany. ${ }^{2}$ Department of Veterinary Medicine, Institute of Immunology, Freie Universität Berlin, Robert-von-Ostertag-Straße 7-13, 14163 Berlin, Germany. ${ }^{3}$ Department of Experimental Animal Facilities and Biorisk Management, Friedrich-Loeffler-Institut, 17493 Greifswald, Insel Riems, Germany.

${ }^{4}$ PathoGuard Consult, Fasanenweg 6, 64342, Seeheim-Jugenheim, Germany.

${ }^{5}$ CSL Behring Biotherapies for Life ${ }^{\text {TM }}$, P.O. Box 1230, 35002 Marburg, Germany.
Received: 7 August 2018 Accepted: 23 November 2018

Published online: 04 December 2018

\section{References}

1. WorldHealthOrganization. Hepatitis E, Fact sheet [updated July 2017]. Available from: http://www.who.int/mediacentre/factsheets/fs280/en/en/.

2. International Committee on Taxonomy of Viruses Hepeviridae Study G, Smith DB, Simmonds P, Jameel S, Emerson SU, Harrison TJ, et al. Consensus proposals for classification of the family Hepeviridae. The Journal of general virology. 2014;95(Pt 10):2223-32.

3. Balayan MS. Epidemiology of hepatitis E virus infection. J Viral Hepat. 1997; 4(3):155-65.

4. Arankalle VA, Chadha MS, Chobe LP, Nair R, Banerjee K. Cross-challenge studies in rhesus monkeys employing different Indian isolates of hepatitis $E$ virus. J Med Virol. 1995;46(4):358-63.

5. Meng X, Purcell R, Halbur P, Lehman J, Webb D, Tsareva T, et al. A novel virus in swine is closley related to the human HEV. Proc Natl Acad Sci U S A 1997;94:6.

6. Khuroo MS, Khuroo MS. Hepatitis E: an emerging global disease - from discovery towards control and cure. J Viral Hepat. 2016;23(2):68-79.

7. Christou L, Kosmidou M. Hepatitis E virus in the Western world--a porkrelated zoonosis. Clin Microbiol Infect. 2013;19(7):600-4.

8. Aspinall EJ, Couturier E, Faber M, Said B, ljaz S, Tavoschi L, et al. Hepatitis E virus infection in Europe: surveillance and descriptive epidemiology of confirmed cases, 2005 to 2015. Euro Surveill. 2017;22(26):13-22.

9. Colson P, Borentain P, Queyriaux B, Kaba M, Moal V, Gallian P, et al. Pig liver sausage as a source of hepatitis $E$ virus transmission to humans. J Infect Dis. 2010;202(6):825-34.

10. Matsubayashi K, Kang JH, Sakata H, Takahashi K, Shindo M, Kato M, et al. A case of transfusion-transmitted hepatitis $\mathrm{E}$ caused by blood from a donor infected with hepatitis E virus via zoonotic food-borne route. Transfusion. 2008;48(7):1368-75.

11. Zhang W, He Y, Wang H, Shen Q, Cui L, Wang X, et al. Hepatitis E virus genotype diversity in eastern China. Emerg Infect Dis. 2010;16(10):1630-2.

12. Dai $X$, Dong $C$, Zhou Z, Liang J, Dong M, Yang Y, et al. Hepatitis E virus genotype 4, Nanjing, China, 2001-2011. Emerg Infect Dis. 2013;19(9):1528-30.

13. Kamar N, Bendall R, Legrand-Abravanel F, Xia N-S, ljaz S, Izopet J, et al. Hepatitis E. Lancet. 2012;379(9835):2477-88.

14. Takahashi K, Kitajima N, Abe N, Mishiro S. Complete or near-complete nucleotide sequences of hepatitis $E$ virus genome recovered from a wild boar, a deer, and four patients who ate the deer. Virology. 2004;330(2):501-5.

15. Rutjes SA, Lodder-Verschoor F, Lodder WJ, van der Giessen J, Reesink H, Bouwknegt $M$, et al. Seroprevalence and molecular detection of hepatitis $E$ virus in wild boar and red deer in the Netherlands. J Virol Methods. 2010; 168(1-2):197-206

16. Zhao C, Ma Z, Harrison TJ, Feng R, Zhang C, Qiao Z, et al. A novel genotype of hepatitis $E$ virus prevalent among farmed rabbits in China. J Med Virol. 2009:81(8):1371-9.

17. Hammerschmidt F, Schwaiger K, Dähnert L, Vina-Rodriguez A, Hoper D, Gareis $M$, et al. Hepatitis E virus in wild rabbits and European brown hares in Germany. Zoonoses Public Health. 2017;64(8):612-22.

18. Thiry D, Mauroy A, Pavio N, Purdy MA, Rose N, Thiry E, et al. Hepatitis E Virus and Related Viruses in Animals. Transbound Emerg Dis. 2015;64(1):37-52.

19. Krumbholz A, Joel S, Neubert A, Dremsek P, Durrwald R, Johne R, et al Age-related and regional differences in the prevalence of hepatitis $E$ virus-specific antibodies in pigs in Germany. Vet Microbiol. 2013:167(34):394-402.

20. Hsieh SY, Meng XJ, Wu YH, Liu ST, Tam AW, Lin DY, et al. Identity of a novel swine hepatitis E virus in Taiwan forming a monophyletic group with Taiwan isolates of human hepatitis E virus. J Clin Microbiol. 1999;37(12): 3828-34.

21. Andraud M, Dumarest M, Cariolet R, Aylaj B, Barnaud E, Eono F, et al. Direct contact and environmental contaminations are responsible for HEV transmission in pigs. Vet Res. 2013;44:102

22. Casas M, Pina S, de Deus N, Peralta B, Martin M, Segales J. Pigs orally inoculated with swine hepatitis $E$ virus are able to infect contact sentinels. Vet Microbiol. 2009:138(1-2):78-84

23. Schlosser J, Eiden M, Vina-Rodriguez A, Fast C, Dremsek P, Lange E, et al. Natural and experimental hepatitis E virus genotype 3-infection in European wild boar is transmissible to domestic pigs. Vet Res. 2014;45:121. 
24. Bouwknegt M, Rutjes SA, Reusken CB, Stockhofe-Zurwieden N, Frankena K, de Jong $\mathrm{MC}$, et al. The course of hepatitis $\mathrm{E}$ virus infection in pigs after contact-infection and intravenous inoculation. BMC Vet Res. 2009:5:7.

25. Halbur PG, Kasorndorkbua C, Gilbert C, Guenette D, Potters MB, Purcel $\mathrm{RH}$, et al. Comparative pathogenesis of infection of pigs with hepatitis E viruses recovered from a pig and a human. J Clin Microbiol. 2001; 39(3):918-23.

26. Lee $\mathrm{YH}, \mathrm{Ha}$ Y, Ahn KK, Chae C. Localisation of swine hepatitis $\mathrm{E}$ virus in experimentally infected pigs. Vet J. 2009;179(3):417-21.

27. Balayan. Brief Repor, Experimental Hepatitis E Infection in Domestic Pigs. 1990.

28. Meng XJ, Halbur PG, Shapiro MS, Govindarajan S, Bruna JD, Mushahwar IK, et al. Genetic and experimental evidence for cross-species infection by swine hepatitis E virus. J Virol. 1998;72(12):9714-21.

29. Bouwknegt M, Frankena K, Rutjes SA, Wellenberg GJ, de Roda Husman AM, van der Poel WH, et al. Estimation of hepatitis E virus transmission among pigs due to contact-exposure. Vet Res. 2008;39(5):40.

30. Szabo K, Trojnar E, Anheyer-Behmenburg H, Binder A, Schotte U, Ellerbroek $L$, et al. Detection of hepatitis $E$ virus RNA in raw sausages and liver sausages from retail in Germany using an optimized method. Int J Food Microbiol. 2015;215:149-56.

31. Di Bartolo I, Angeloni G, Ponterio E, Ostanello F, Ruggeri FM. Detection of hepatitis E virus in pork liver sausages. Int J Food Microbiol. 2015;193:29-33.

32. Lapa D, Capobianchi MR, Garbuglia AR. Epidemiology of hepatitis E virus in European countries. Int J Mol Sci. 2015;16(10):25711-43.

33. Krumbholz A, Mohn U, Lange J, Motz M, Wenzel JJ, Jilg W, et al. Prevalence of hepatitis $E$ virus-specific antibodies in humans with occupational exposure to pigs. Med Microbiol Immunol. 2012;201(2): 239-44.

34. Meng XJ, Wiseman B, Elvinger F, Guenette DK, Toth TE, Engle RE, et al. Prevalence of antibodies to hepatitis $E$ virus in veterinarians working with swine and in Normal blood donors in the United States and other countries. J Clin Microbiol. 2002;40(1):117-22.

35. Aggarwal R. Clinical presentation of hepatitis E. Virus Res. 2011;161(1):15-22.

36. Ankcorn MJ, Tedder RS. Hepatitis E: the current state of play. Transfus Med. 2017;27(2):84-95.

37. Kamar N, Selves J, Mansuy JM, Ouezzani L, Peron JM, Guitard J, et al. Hepatitis $\mathrm{E}$ virus and chronic hepatitis in organ-transplant recipients. N Engl J Med. 2008;358(8):811-7.

38. Dalton HR, Bendall RP, Keane FE, Tedder RS, ljaz S. Persistent carriage of hepatitis E virus in patients with HIV infection. N Engl J Med. 2009;361(10): 1025-7.

39. Vina-Rodriguez A, Schlosser J, Becher D, Kaden V, Groschup MH, Eiden M. Hepatitis E virus genotype 3 diversity: phylogenetic analysis and presence of subtype 3b in wild boar in Europe. Viruses. 2015;7(5):2704-26.

40. Kärber G. Beitrag zur kollektiven Behandlung pharmakologischer Reihenversuche. Naunyn-Schmiedeberg's Arch Exp Pathol Pharmakol. 1931; 162(4):480-3.

41. Spearman C. The method of "right and wrong cases" (constant stimuli) without Gauss's formula. Br J Psychol. 1908;2:227-42.

42. Satake M, Matsubayashi K, Hoshi Y, Taira R, Furui $Y$, Kokudo N, et al. Unique clinical courses of transfusion-transmitted hepatitis $E$ in patients with immunosuppression. Transfusion. 2017;57(2):280-8.

43. Rossi F. Reflection paper on viral safety of plasma-derived medicinal products with respect to hepatitis E virus. Committee for Medicinal Products for Human Use (CHMP). 2015(EMA/CHMP/BWP/723009/2014).

44. van de Garde MD, Pas SD, van der Net G, de Man RA, Osterhaus AD, Haagmans BL, et al. Hepatitis E virus (HEV) genotype 3 infection of human liver chimeric mice as a model for chronic HEV infection. J Virol. 2016;90(9): 4394-401.

45. Roques P, Gardinali NR, Guimarães JR, Melgaço JG, Kevorkian YB, FDO B, et al. Cynomolgus monkeys are successfully and persistently infected with hepatitis E virus genotype 3 (HEV-3) after long-term immunosuppressive therapy. PloS one. 2017;12(3):e0174070.

46. Geng Y, Zhao C, Huang W, Harrison TJ, Zhang H, Geng K, et al. Detection and assessment of infectivity of hepatitis E virus in urine. J Hepatol. 2016; 64(1):37-43

47. Choi YH, Zhang X, Tran C, Skinner B. Expression profiles of host immune response-related genes against HEV genotype 3 and genotype 1 infections in rhesus macaques. J Viral Hepat. 2018;25(8):986-95.
48. Schlosser J, Vina-Rodriguez A, Fast C, Groschup MH, Eiden M. Chronically infected wild boar can transmit genotype 3 hepatitis $\mathrm{E}$ virus to domestic pigs. Vet Microbiol. 2015;180(1-2):15-21.

49. Nagashima S, Takahashi M, Kobayashi T, Tanggis, Nishizawa T, Nishiyama T, et al. Characterization of the Quasi-Enveloped Hepatitis E Virus Particles Released by the Cellular Exosomal Pathway. J Virol. 2017;91(22):e00822-17.

50. Takahashi M, Yamada K, Hoshino Y, Takahashi H, Ichiyama K, Tanaka T, et al. Monoclonal antibodies raised against the ORF3 protein of hepatitis E virus (HEV) can capture HEV particles in culture supernatant and serum but not those in feces. Arch Virol. 2008;153(9):1703-13.

51. Okamoto H. Culture systems for hepatitis E virus. J Gastroenterol. 2013;48(2): 147-58.

52. Qi Y, Zhang F, Zhang L, Harrison TJ, Huang W, Zhao C, et al. Hepatitis E virus produced from cell culture has a lipid envelope. PLoS One. 2015;10(7): e0132503.

53. Chapuy-Regaud S, Dubois M, Plisson-Chastang C, Bonnefois T, Lhomme S, Bertrand-Michel J, et al. Characterization of the lipid envelope of exosome encapsulated HEV particles protected from the immune response. Biochimie. 2017;141:70-9.

54. Yin X, Ambardekar C, Lu Y, Feng Z. Distinct entry mechanisms for nonenveloped and quasi-enveloped hepatitis E viruses. J Virol. 2016;90(8): 4232-42.

55. Tian DY, Chen Y, Xia NS. Significance of serum IgA in patients with acute hepatitis E virus infection. World J Gastroenterol. 2006;12(24):3919-23.

56. Zhang S, Tian D, Zhang Z, Xiong J, Yuan Q, Ge S, et al. Clinical significance of anti-HEV IgA in diagnosis of acute genotype 4 hepatitis $E$ virus infection negative for anti-HEV IgM. Dig Dis Sci. 2009;54(11):2512-8.

57. Salines M, Barnaud E, Andraud M, Eono F, Renson P, Bourry O, et al. Hepatitis E virus chronic infection of swine co-infected with porcine reproductive and respiratory syndrome virus. Vet Res. 2015;46:55.

58. Emerson SU, Clemente-Casares P, Moiduddin N, Arankalle VA, Torian U, Purcell RH. Putative neutralization epitopes and broad cross-genotype neutralization of hepatitis $E$ virus confirmed by a quantitative cell-culture assay. The Journal of general virology. 2006;87(Pt 3):697-704.

59. Tang ZM, Tang M, Zhao M, Wen GP, Yang F, Cai W, et al. A novel linear neutralizing epitope of hepatitis E virus. Vaccine. 2015;33(30):3504-11.

60. Takahashi M, Hoshino Y, Tanaka T, Takahashi H, Nishizawa T, Okamoto H. Production of monoclonal antibodies against hepatitis E virus capsid protein and evaluation of their neutralizing activity in a cell culture system. Arch Virol. 2008;153(4):657-66.

61. Kamar N, Rostaing L, Legrand-Abravanel F, Izopet J. How should hepatitis E virus infection be defined in organ-transplant recipients? Am J Transplant. 2013;13:2.

62. Wernike K, Hoffmann B, Beer M. Single-tube multiplexed molecular detection of endemic porcine viruses in combination with Backgreound screening for Transbopundery diseases. J Clin Microbiol. 2013;51(3):7.

63. Hoffmann B, Depner K, Schirrmeier H, Beer M. A universal heterologous internal control system for duplex real-time RT-PCR assays used in a detection system for pestiviruses. J Virol Methods. 2006;136(1-2):200-9.

64. Jothikumar N, Cromeans TL, Robertson BH, Meng XJ, Hill VR. A broadly reactive one-step real-time RT-PCR assay for rapid and sensitive detection of hepatitis E virus. J Virol Methods. 2006;131(1):65-71.

\section{Ready to submit your research? Choose BMC and benefit from:}

- fast, convenient online submission

- thorough peer review by experienced researchers in your field

- rapid publication on acceptance

- support for research data, including large and complex data types

- gold Open Access which fosters wider collaboration and increased citations

- maximum visibility for your research: over $100 \mathrm{M}$ website views per year

At BMC, research is always in progress.

Learn more biomedcentral.com/submissions 